\title{
AETIOLOGY OF HAEMOPTYSIS IN PATIENTS PRESENTING TO A TERTIARY CARE CENTRE IN SOUTH INDIA
}

\author{
Ronald Win $B^{1}$, Smitha P. S
}

${ }^{1}$ Additional Professor, Department of Pulmonary Medicine, Government Medical College, Trivandrum.

${ }^{2}$ Assistant Surgeon, Kerala Government Health Service.

\section{ABSTRACT}

\section{BACKGROUND}

Haemoptysis is the expectoration of blood from the lower respiratory tract. It can arise from any part of the respiratory tract, from the alveoli to the glottis. It is important, to distinguish haemoptysis from epistaxis. Haemoptysis can range from blood-tinged sputum to life-threatening large volumes of bright red blood. For most patients, any degree of haemoptysis can be anxietyproducing and often prompts medical evaluation.

The objectives of this study were-1) to determine the proportion of patients presenting with different aetiology of haemoptysis and 2) to find out the association between aetiology and severity of haemoptysis.

\section{MATERIALS AND METHODS}

Hospital based descriptive study conducted in the Department of Pulmonary Medicine, Government Medical College Hospital, Thiruvananthapuram from February 2013 to August 2014. All patients with expectoration (coughing up) of blood or blood stained sputum attending the Department of Pulmonary Medicine were recruited. Sputum examination and Chest X-ray done in all patients. HRCT and Fibreoptic Bronchoscopy when diagnosis was inconclusive, and sputum cytology in suspected case of malignancy.

\section{RESULTS}

257 cases of haemoptysis were analysed. Out of these, 27\% were Post TB Bronchiectasis. Consolidation and Bronchiectasis were $14 \%$ each. Malignancy and Tuberculosis forms the next common cause of haemoptysis. In this study, 1.5\% of cases the aetiology was unknown.

\section{CONCLUSION}

Post TB bronchiectasis was the commonest cause of haemoptysis followed by consolidation, malignancy, bronchiectasis and tuberculosis were; the next four common cause of blood streaking and moderate haemoptysis. Etiology in patients with normal chest $\mathrm{X}$ ray were acute bronchitis, adenoma and one case of catemenial haemoptysis. Massive haemoptysis was present in 12 patients; which include Post TB bronchiectasis, and sputum positive pulmonary tuberculosis.

\section{KEYWORDS}

Aetiology Haemoptysis Tertiary Care Centre.

HOW TO CITE THIS ARTICLE: Win BR, Smitha PS. Aetiology of haemoptysis in patients presenting to a tertiary care centre in South India. J. Evolution Med. Dent. Sci. 2017;6(10):765-769, DOI: 10.14260/Jemds/2017/166

\section{BACKGROUND}

Haemoptysis is defined as the expectoration of blood derived from the lungs or bronchial tree as a result of pulmonary or bronchial haemorrhage. ${ }^{1}$ It is a frightening symptom for patients and often is a manifestation of a significant underlying disease such as bronchogenic carcinoma. The material and amount produced varies from mere blood streaking of expectorated sputum to massive volumes of pure blood. Expectoration of even a relatively small amount of blood is an alarming symptom and massive haemoptysis can be a life threatening event.

Financial or Other, Competing Interest: None.

Submission 15-12-2016, Peer Review 19-01-2017,

Acceptance 25-01-2017, Published 02-02-2017.

Corresponding Author:

Dr. Ronald Win B,

Additional Professor,

Department of Pulmonary Medicine,

Government Medical College,

Trivandrum.

E-mail: ronaldwin_b@yahoo.co.in

DOI: $10.14260 /$ jemds $/ 2017 / 166$

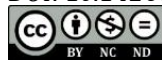

Therefore, haemoptysis of any degree needs thorough evaluation. ${ }^{2}$ The frequency of each disease as a cause of haemoptysis varies in different series, according to the geographical area. Haemoptysis is a nonspecific symptom and can occur in about 100 different clinical conditions. Pulmonary tuberculosis is an important cause of haemoptysis in developing countries whereas in developed countries bronchiectasis, lung cancer and bronchitis are the main causes. Massive haemoptysis is a potentially lethal condition that deserves to be investigated thoroughly and brought under control promptly. Fewer than $5 \%$ of patients presenting with haemoptysis expectorate large volumes of blood. ${ }^{3}$ This can be life threatening either as a result of compromised gas exchange or because of circulatory collapse secondary to acute blood loss. ${ }^{2}$ The associated mortality ranging from $7 \%$ to $30 \% .{ }^{4}$ Haemoptysis is a symptom which demands prompt and efficient investigation. It is important to appreciate the merits and limitation of various investigative procedures available, so that they can be employed in the most logical and economical manner. The cause of haemoptysis is diagnosed in combination of history, physical examination, chest radiography, fiberoptic bronchoscopy, CT 
scan, microbiology and histology. Despite the high sensitivity of HRCT, the cause for the haemoptysis remains un-known in $5 \%$ to $10 \%$ of patients evaluated with HRCT. ${ }^{5}$ The present study was conducted to find out different causes of haemoptysis and the relation between severity and different aetiology of haemoptysis.

\section{Aim and Objectives \\ Primary Objective}

To determine the proportion of patients presenting with different aetiologies of haemoptysis in the Department of Pulmonary Medicine, Government Medical College Hospital, Thiruvananthapuram.

\section{Secondary Objective}

To find out the association between aetiology and severity of haemoptysis.

\section{MATERIALS AND METHODS}

Study Design

Descriptive study.

\section{Study Period}

February 2013 to August 2014.

\section{Study Setting}

Department of Pulmonary Medicine, Medical College Hospital Thiruvananthapuram.

\section{Study Population}

All patients presenting with haemoptysis in Department of Pulmonary Medicine, Medical College Thiruvananthapuram during the study period.

\section{Inclusion Criteria}

All haemoptysis patients presented in the Department of Pulmonary Medicine, Medical College Thiruvananthapuram who are willing to take part in the study during the study period

\section{Exclusion Criteria}

Patients not willing to participate in the study.

\section{Methods}

Total 257 patients with complaints of haemoptysis attending the Department of Pulmonary Medicine, Medical College, Thiruvananthapuram between a period of Feb 2013 to August 2014 were included. All patients who were willing to take part in the study were recruited after obtaining informed consent. Apart from patient's personal details, history regarding smoking, previous history of tuberculosis and haemoptysis were elicited and recorded in the Performa. By careful history taking hematemesis was ruled out. In doubtful cases of URT bleed ENT examination was done. In suspected cases of hematemesis, the blood was examined for the presence of food particles and colour. Every patient was asked to collect the expectorated blood in a container. The amount of haemoptysis was recorded and converted to a millilitre equivalent i.e. one glass $=200 \mathrm{ml}$.
Depending on the amount Expectorated, Haemoptysis was Classified as-

a) Streaky.

b) Moderate.

c) Massive.

Mild ( $<100 \mathrm{ml} /$ day), Moderate (100-400 ml/day), and massive ( $>400 \mathrm{ml} /$ day or $150 \mathrm{ml}$ in a single bout).

Routine investigations like $\mathrm{Hb}, \mathrm{TC}, \mathrm{DC}$, ESR routine urine examination, LFT, RFT, sputum AFB for 2 days, and chest Xray were done in all patients. Bleeding time, clotting time, peripheral smear in suspected cases of bleeding diathesis. ECG, and ECHO were done in selected cases. Sputum cytology in all sputum negative patients who are smokers with or without clubbing. CT chest and fiberoptic bronchoscopy were done in patients with and without chest X-ray lesion. Bronchial washing, brushing and biopsy were done in indicated cases. Fine needle aspiration cytology in those patients who had CT chest showing peripheral lung lesions. About 6 patients were underwent FNAC lung.

\section{OBSERVATIONS AND RESULTS}

Total number of patients with haemoptysis included in this study were 257 during the study period from February 2013 to August 2014.

\begin{tabular}{|c|c|c|c|}
\hline Age & Male & Female & Total \\
\hline$<20$ & 3 & 1 & 4 \\
\hline $20-29$ & 11 & 5 & 16 \\
\hline $30-39$ & 11 & 4 & 15 \\
\hline $40-49$ & 36 & 12 & 48 \\
\hline $50-59$ & 51 & 10 & 61 \\
\hline $60-69$ & 70 & 14 & 84 \\
\hline $70-79$ & 19 & 2 & 21 \\
\hline 80 and above & 8 & 0 & 8 \\
\hline Total & $\mathbf{2 0 9}$ & $\mathbf{4 8}$ & $\mathbf{2 5 7}$ \\
\hline \multicolumn{4}{|c|}{ Table 1 } \\
\hline
\end{tabular}

\section{Age Distribution According to Sex}

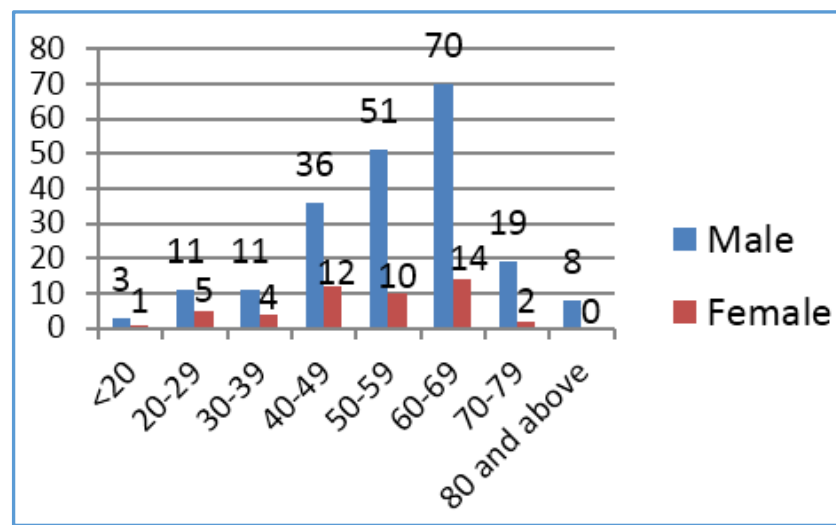

Figure 1. Majority of patients were in the age group 50-70 yrs (56.4\%)

Percentage Distribution of the Sample According to Age-

- Mean-54.45.

- Median- 58.

- $\quad$ Range-15-85. 


\section{Sex Distribution}

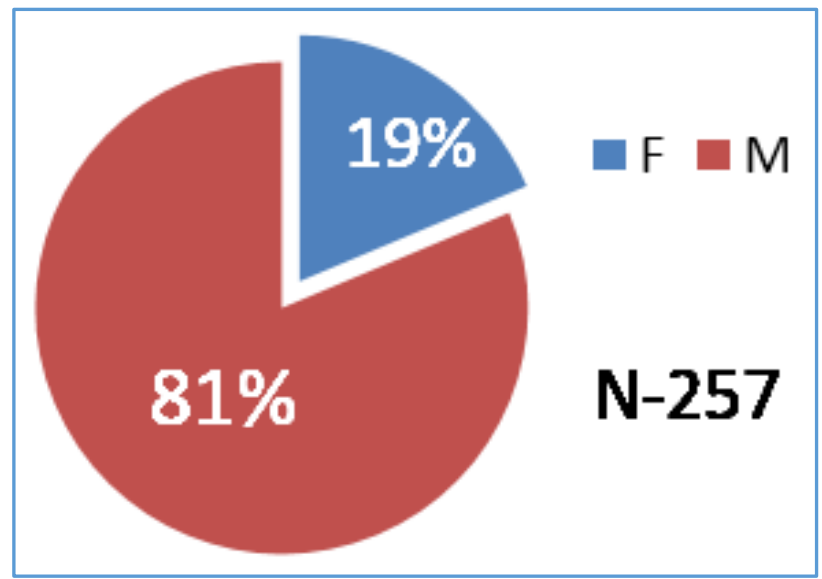

Figure 2. There was male predominance in the study with M: F ratio of 4.35:1

Distribution of Patients by Smoking Index Total smokers 162

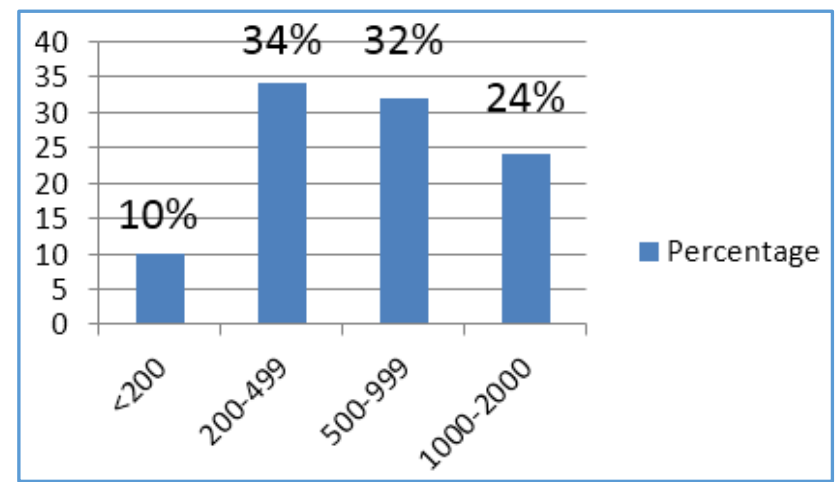

Figure $3.76 .5 \%$ of males were smokers. Two females were smokers with Smoking index 750 and 300

\begin{tabular}{|c|c|c|c|c|}
\hline Smoking Index & Male & Female & Total & $\%$ \\
\hline$<200$ & 16 & 0 & 16 & $10 \%$ \\
\hline $200-499$ & 54 & 1 & 55 & $34 \%$ \\
\hline $500-999$ & 51 & 1 & 52 & $32 \%$ \\
\hline $1000-2000$ & 39 & 0 & 39 & $24 \%$ \\
\hline Total & 160 & 2 & 162 & \\
\hline \multicolumn{5}{|c|}{ Table 2 } \\
\hline
\end{tabular}

The commonest comorbidity seen was diabetics $16 \%$.

\section{Severity of Haemoptysis}

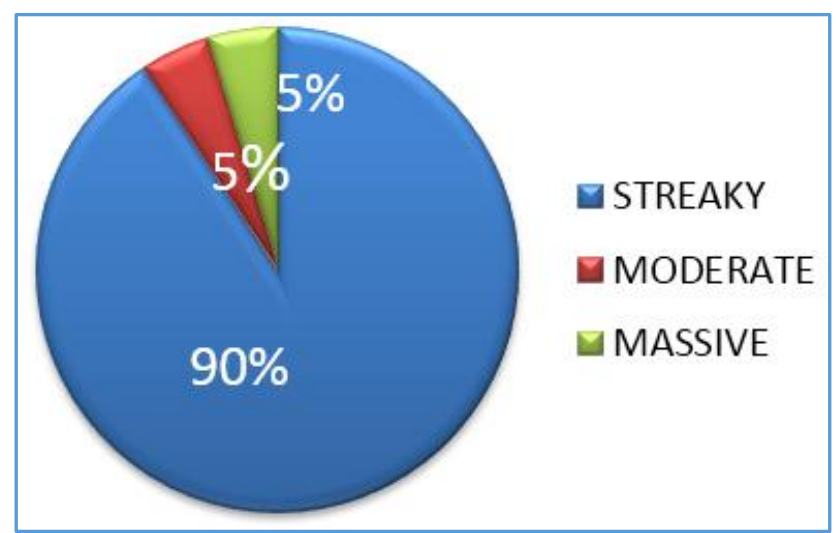

Figure 4. 90\% of patients had streaky haemoptysis. Patients with moderate haemoptysis had $100 \mathrm{ml}-<400$ ml/day. $5 \%$ of patients had massive haemoptysis i.e. $>400 \mathrm{ml} /$ day
Sputum Positive Pulmonary Tuberculosis

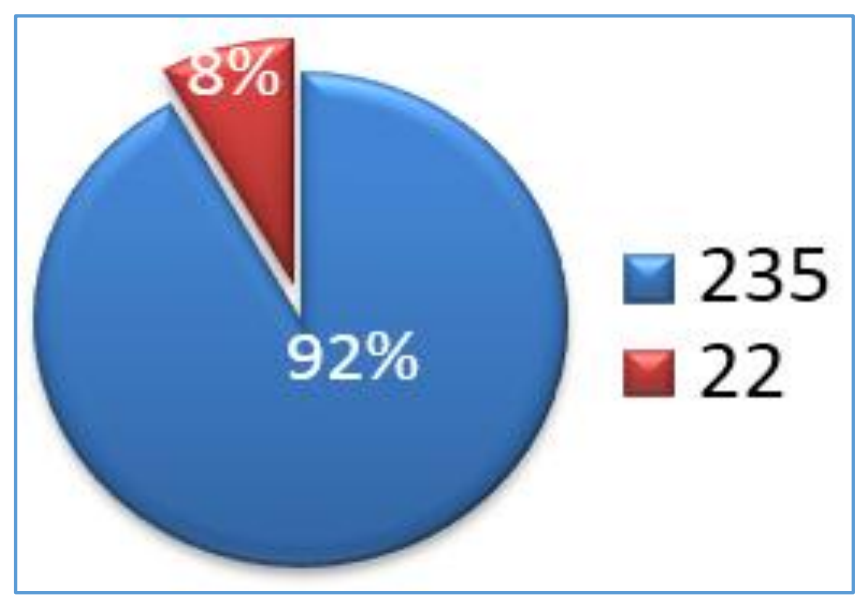

Figure 5

Among 257 patients, 22 patients (8\%) had new sputum positive pulmonary tuberculosis. 82 patients had previous history of pulmonary TB.

In Patient who were diagnosed as smear positive pulmonary TB apart from routine blood investigations and chest $\mathrm{x}$ ray no further investigations were done.

Out of 22 Patients Lesion in Chest $x$ ray.

- 14 upper zone lesion.

- 8 - multilobar consolidation.

Recurrent Haemoptysis

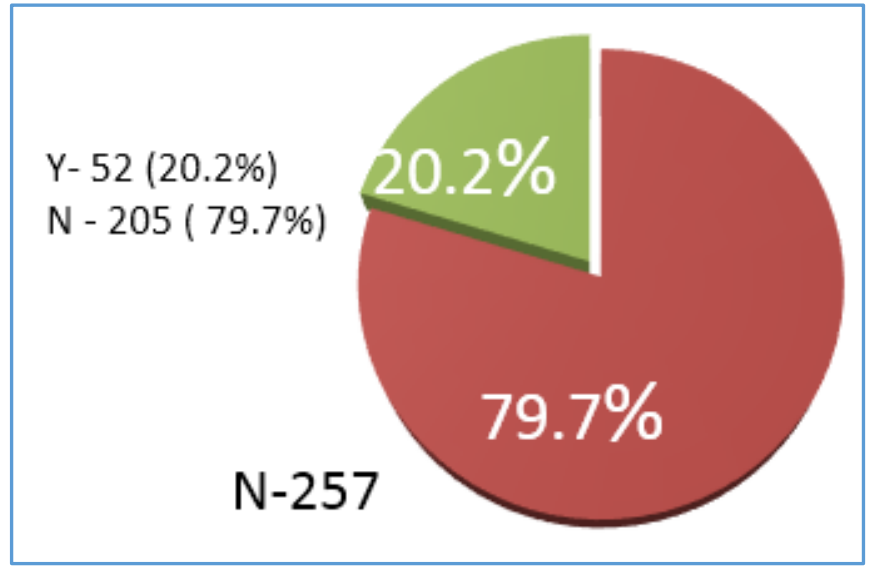

Figure 6

\section{Normal Chest X Ray}

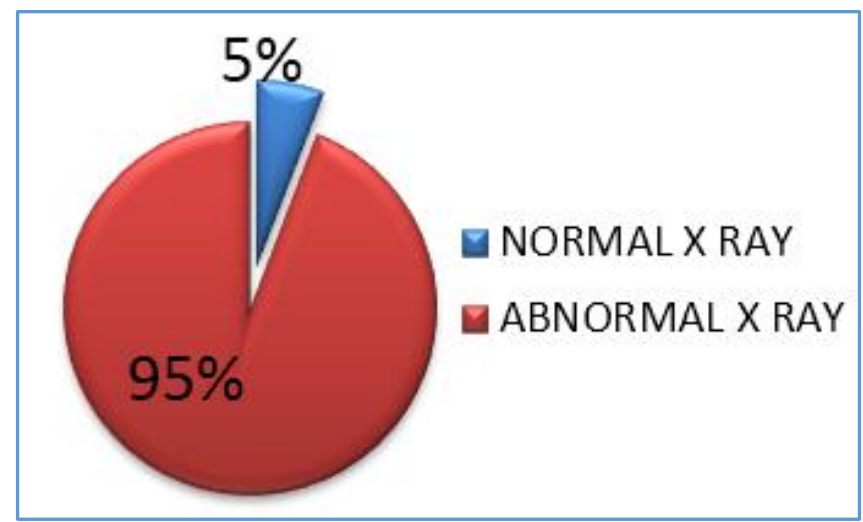

Figure 7 
Patients with normal chest X-ray where further investigated with HRCT chest and Bronchoscopy.

\section{Sputum Cytology}

Done in 75 patients.

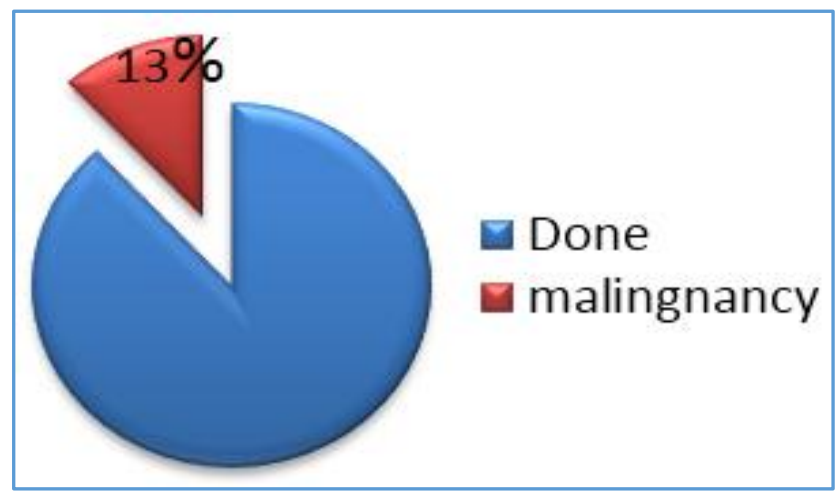

Figure 8

Patients with atypical cells in sputum cytology were underwent bronchoscopy.

Here the predominant lesion was NSCLC.

\section{Chest CT Lesions}

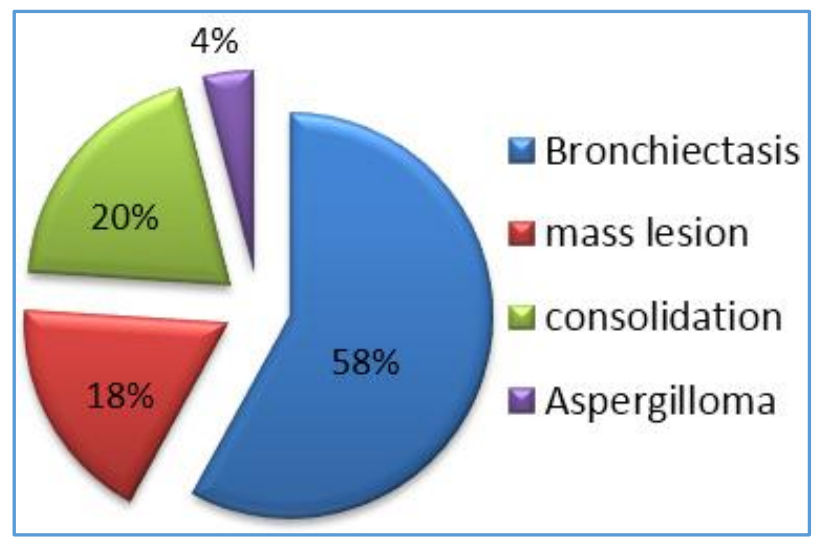

Figure 9

- Among the patients who had done CT chest 58\% of patients had bronchiectasis.

- Mass lesion found in $18 \%$ of cases.

- Consolidation was found in $20 \%$ of patients.

- Aspergilloma seen in $4 \%$ of patients.

\section{Fiber Optic Bronchoscopy}

Done in 54 patients. Out of this, 27 cases showed malignant growth.

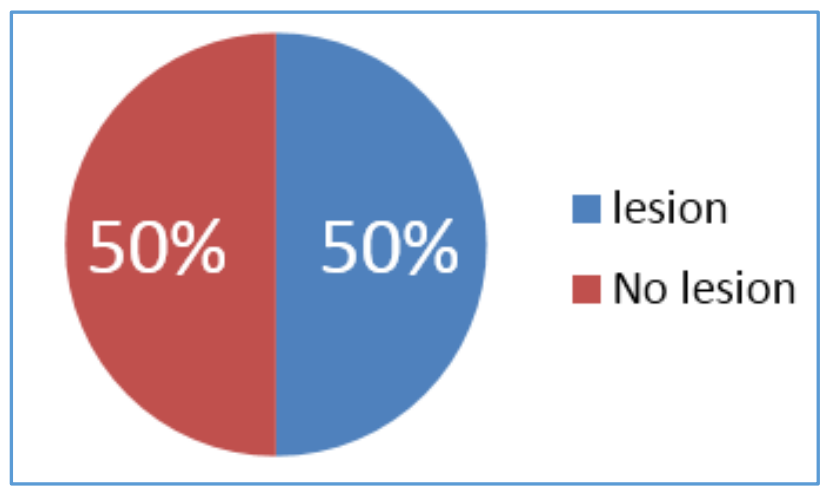

Figure 10

\section{Graph Showing Distribution of Aetiology}

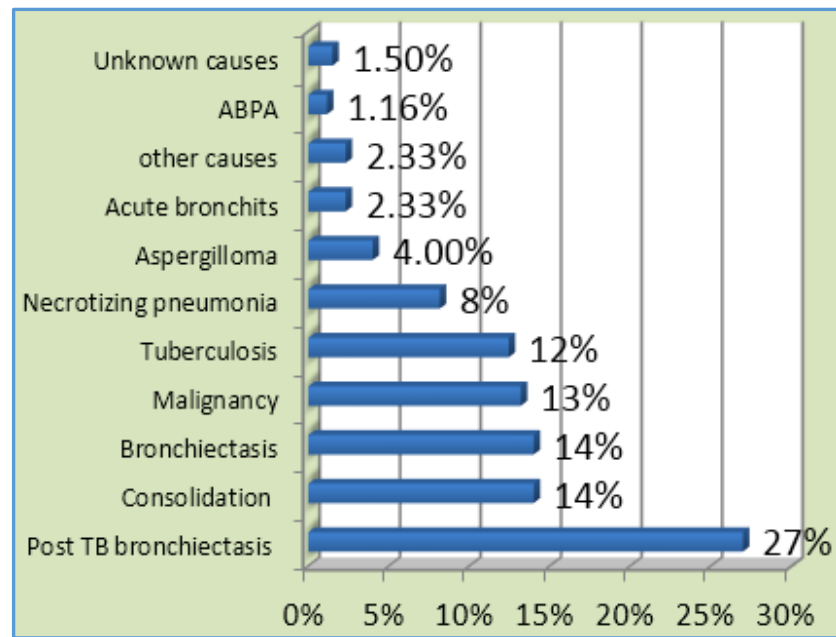

Figure 11

\section{DISCUSSION}

In this descriptive study, various aetiology of haemoptysis were evaluated in patients attending the tertiary care centre. All patients with complaints of haemoptysis were admitted and evaluated as inpatients. A total of 257 patients with haemoptysis were included in the study.

Analysis of age distribution showed that the study population had an age distribution of 40-70 yrs. A minimum age of 15 years and maximum age of 85 years was seen. Haemoptysis may be present in both young and old. There was a Male predominance in the study group (81\% males and $19 \%$ females). There is no correlation between severity of haemoptysis and high smoking index. The severity of haemoptysis was categorized as streaky which is seen in $90 \%$ of patients. Moderate haemoptysis was seen in 5\% and massive in another $5 \%$ of patients. According to published data, in any given year $28 \%$ of pulmonologists witness a case of death due to massive haemoptysis.6,7 The source of massive haemoptysis is usually located in the bronchial arteries $(90 \%$ of cases). In $5 \%$ of patients, it is located in the pulmonary arteries $^{7}$ and in the remaining $5 \%$ it is located in the aorta (aortobronchial fistulae or rupture of aortic aneurysms) or the systemic arterial circulation (branches serving the lungs).8,9

Death due to massive haemoptysis occurred in 4 patients. Out of these, 2 patients were sputum positive pulmonary tuberculosis and one post TB bronchiectasis, Fourth condition was a case of diffuse alveolar haemorrhage. Boaz Hirshberg B et al described a mortality rate of $2.5 \%, 6 \%$, and $38 \%$ for mild moderate and massive haemoptysis respectively. 10 While a retrospective study of 63 patients by Van Kralingen et al reported a mortality rate of $6 \%$ among patients with massive haemoptysis. 11

In the present study, diagnosis could be established in $98.4 \%$ cases while $1.6 \%$ remained in the category of cryptogenic haemoptysis. (Undiagnosed case study). Out of the total haemoptysis cases, 20 patients required ICU Care and 6 cases were intubated and mechanically ventilated. The drugs used to control haemoptysis includes haemostatic agents, antibiotics, blood transfusion, anti-tuberculosis chemotherapy, supportive measures and specific treatment for the aetiology of haemoptysis. 
The commonest aetiology identified were post tubercular bronchiectasis 27\%, consolidation 14\%, Bronchiectasis 14\% (other than Post TB Bronchiectasis), Malignancy 13\%, tuberculosis $12 \%$ with sputum positive pulmonary TB $8 \%$ and smear negative pulmonary TB of $4 \%$. Necrotizing pneumonia $8 \%$, Aspergilloma $4 \%$. Acute bronchitis 2.33\%, other causes $2.33 \%$, ABPA $1.16 \%$, unknown causes $1.5 \%$. Other causes include Bronchial adenoma, mucocele, Catemenial haemoptysis. Diffuse alveolar haemorrhage, Amyloidosis etc. In this study 8 patients with haemoptysis underwent bronchial artery embolization and Lobectomy in one patient.

Those patients not diagnosed by conventional methods were evaluated with HRCT scan, bronchoscopy and diagnosis was obtained in 16 patients. An additional yield in diagnosis was obtained in $6.8 \%$, which includes adenoma, acute bronchitis, catemenial haemoptysis and minimal bronchiectasis. Various authors have described a diagnostic yield of (30-70\%) in evaluating patients with haemoptysis and a normal chest $\mathrm{x}$ ray. ${ }^{12} \mathrm{~A}$ study by Damini $\mathrm{G}$ et al who evaluated the role of CT scan and Bronchoscopy in diagnosing inflammatory conditions causing haemoptysis showed diagnosis of $97 \%$. of cases. Another study by Khezorollah with 50 patients having haemoptysis and normal chest X-ray, a definite diagnosis was made in 45 patients (90\%).13 The diagnosis was made by high resolution CT in 19 patients (38\%) and by FOB in another 18 (36\%), and rest of the cases by conventional method. ${ }^{13}$

\section{CONCLUSION}

Post TB bronchiectasis was the commonest cause of haemoptysis in patients attending the tertiary care center.

Consolidation including necrotizing pneumonia forms the second most common cause of haemoptysis.

This is followed by lung malignancy, bronchiectasis and tuberculosis as the next three common cause of blood streaking and moderate haemoptysis.

Patients with normal chest X-ray were underwent CT and bronchoscopy and the predominant causes were acute bronchitis, adenoma and one case of catemenial haemoptysis.

Most common lesion in CT was Bronchiectasis 58\%, consolidation $20 \%$, Mass lesion $18 \%$ and aspergilloma $4 \%$. Etiology of $1.5 \%$ of total haemoptysis were unknown.

Massive haemoptysis was present in 12 patients with post TB Bronchiectasis. The main cause was post TB bronchiectasis, and sputum positive pulmonary tuberculosis.

Death due to massive haemoptysis occurred in 4 patients and the common etiology was sputum positive pulmonary TB.

Bronchial artery embolisation was done in 8 patients and lobectomy in one patient.

\section{REFERENCES}

[1] Prasad R, Garg R, Srivastava P. Lessons from patients with haemoptysis attending a chest clinic in India. Ann Thorac Med 2009;4(1):10-12.

[2] Stedman TL. Stedman's medical dictionary. 27 th edn. Philidelphia: Lipincott Williams and Wilkins 2000.

[3] Fishman AP, Elias JA, Fishman JA, et al. Syptoms and signs of respiratory disease. In: Fishman's pulmonary diseases and disorders. $4^{\text {th }}$ edn, Vol. I, Part III. McGraw Hill Professional 2008.

[4] Mukhopadhyaya S, Sood R. Approach to a patient with haemoptysis and normal chest x-ray. JIACM 2002;3(1):14-22.

[5] Magu S, Malhotra R, Gupta KB, et al. Role of computed tomography in patients with haemoptysis and a normal chest skiagram. Indian J Chest Dis Allied Sci 2000;42(2):101-4.

[6] Haponik EF, Fein A, Chin R. Managing life-threatening haemoptysis: has anything really changed? Chest 2000;118(5):1431-5.

[7] Hakanson E, Konstantinov IE, Fransson SG, et al. Management of life-threatening haemoptysis. $\mathrm{Br} \mathrm{J}$ Anaesth 2002;88(2):291-5.

[8] Macintosh EL, Parrott JC, Unruh HW. Fistulas between the aorta and tracheobronchial tree. Ann Thorac Surg 1991;51(3):515-9.

[9] Pearse EO, Bryan AJ. Massive haemoptysis 27 years after surgery for coarctation of the aorta. J R Soc Med 2001;94(12):640-1.

[10] Hirshberg B, Biran I, Glazer M, et al. Haemoptysis: etiology, evaluation, and outcome in a tertiary referral hospital. Chest 1997;112(2):440-4.

[11] Van Kralingen KW, Zimmerman M, Postmus PE, et al. Management of haemoptysis in third world city hospital: retrospective study. Tuber Lung Dis 1995;76(4):344-8.

[12] Miller AB, Boothroyd AE, Edwards D, et al. Role of computed tomography (CT) in investigating unexplained haemoptysis. Respir Med 1992;86(1):3944.

[13] Khezrollah B. Determination of etiology of haemoptysis in patients with normal chest radiograph: bronchoscopy/high resolution CT scan correlation. The Internet Journal of Pulmonary Medicine $2001 ; 2(2)$. 